\title{
Odległe efekty głosowe u osób z jednostronnym porażeniem fałdów głosowych leczonych metodą laryngoplastyki iniekcyjnej
}

\section{Long-term follow up in injection laryngoplasty in patients with unilateral vocal fold paresis}

\author{
Beata Miaśkiewicz ${ }^{1}$, Agata Szkiełkowska ${ }^{1,2}$ \\ ${ }^{1}$ Instytut Fizjologii i Patologii Słuchu, Światowe Centrum Słuchu, Warszawa/Kajetany \\ ${ }^{2}$ Uniwersytet Muzyczny Fryderyka Chopina, Katedra Audiologii i Foniatrii, Warszawa
}

Adres autora: Beata Miaśkiewicz, Instytut Fizjologii i Patologii Słuchu, Światowe Centrum Słuchu, ul. Mokra. 17, Kajetany, 05-830 Nadarzyn, e-mail: b.miaskiewicz@ifps.org.pl

\section{Streszczenie}

Wprowadzenie: Jednostronne porażenie fałdu głosowego może mieć różną etiologię, jednak zwykle prowadzi do zaburzeń głosu o zmiennym stopniu nasilenia, zaburzeń połykania czy aspiracji. Metody leczenia obejmują rehabilitację głosu, chirurgię szkieletu krtani oraz laryngoplastykę iniekcyjną i mogą być stosowane osobno lub uzupełniać się.

Cel pracy: Celem pracy była analiza struktury akustycznej głosu u pacjentów z jednostronnym porażeniem fałdu głosowego leczonych chirurgicznie metodą laryngoplastyki iniekcyjnej.

Materiał i metody: Grupę badana stanowiły 42 osoby z jednostronnym porażeniem fałdu głosowego w wieku 21-77 lat. Przed leczeniem i po leczeniu u wszystkich badanych przeprowadzono badanie wideostroboskopowe krtani, percepcyjną ocenę głosu w skali GRBAS i obiektywną akustyczną analizę głosu MDVP (ang. Multidimensional Voice Program). U wszystkich wykonano zabieg laryngoplastyki iniekcyjnej. Badania kontrolne wykonywano 12 i 24 miesiące po operacji.

Wyniki: Percepcyjna ocena głosu przeprowadzona 12 miesięcy po zabiegu wykazała poprawę w zakresie wszystkich ocenianych parametrów. Uzyskano istotną statystycznie poprawę wartości analizowanych parametrów oceniających zaburzenia częstotliwości i względnych pomiarów hałasu oraz zmniejszenie wartości parametrów amplitudowych. Stabilne wyniki utrzymywały się w kolejnym okresie obserwacji.

Wnioski: Metoda laryngoplastyki iniekcyjnej skutecznie poprawia jakość głosu u pacjentów z niedomykalnością fonacyjną głośni. Trwały efekt głosowy wskazuje na długotrwałe działanie zastosowanego materiału iniekcyjnego. Właściwy dobór kryteriów kwalifikacyjnych warunkuje skuteczność i trwałość leczenia.

Słowa kluczowe: jednostronne porażenie fałdu głosowego • niewydolność głośni • augmentacja • kwas hialuronowy

Abstract

Introduction: Unilateral vocal fold paralysis result from multiple etiology and leads to glottal insufficiency. It can result in dysphonia, aspiration or dysphagia. There are many treatment modalities as voice therapy, laryngeal framework surgery, injection augmentation, and combinations of these methods.

Aim: To assess the quality of voice of patients who were treated with the surgical method of hyaluronic acid injection into the vocal fold in the long-term follow up.

Materials and methods: The material included 42 patients (21-77 y.o.) suffering from dysphonia in the course of unilateral vocal fold paralysis, who were referred for injection laryngoplasty. Preoperative and postoperative examination were based on laryngovideostroboscopy, patients' voice was assessed using the subjective GRBAS scale as well as objective evaluation provided by Multidimensional Voice Program (MDVP) was applied. The self-assessment of voice was made by Voice Handicap Index 
(VHI). All patients underwent medialization laryngoplasty with injection of hyaluronic acid into the vocal folds. Voice therapy was continued out for 1-3 months after injection. Follow-up examinations were conducted 12 and 24 months after injection.

Results: The postoperative LVS examination showed that in all cases the phonatory gap was partially (44\%) or totally closed (56\%). Perceptual voice quality assessed by the GRBAS scale was statistically improved and the results were stabile in long term follow up periods. Multidimensional Voice Analysis showed significant statistical improvement within the group of frequency and decreased values of amplitude and noise parameters. The differences in value between follow up periods were not statistically significant.

In observed follow up periods we found improvement of VHI scores.

Conclusions: Injection laryngoplasty improves acoustic characteristic of voice in patients with unilateral vocal fold paralysis. Stabile voice improvement indicates the long-lasting effect of injection laryngoplasty with using of hyaluronic acid. Appropriate qualification criteria are essential for effectiveness of injection laryngoplasty.

Key words: unilateral vocald fold paresis • glottis insufficiency • augmentation • hyaluronic acid

\section{Wstęp}

Etiologia jednostronnego porażenia fałdów głosowych jest różnorodna i jest następstwem czasowego lub trwałego zaburzenia funkcji nerwu krtaniowego wstecznego. Rokowanie co do powrotu czynności nerwu w znacznym stopniu zależy od przyczyny uszkodzenia. Niezależnie od etiologii, zwykle powoduje zaburzenia głosu o zmiennym stopniu nasilenia, zaburzenia połykania czy aspirację. Metody leczenia obejmują rehabilitację głosu, chirurgię szkieletu krtani oraz laryngoplastykę iniekcyjną i mogą być stosowane osobno lub uzupełniać się.

Jedną z najczęściej stosowanych współcześnie metod leczenia jest implantacja materiałów allogennych do fałdów głosowych. Laryngoplastyka iniekcyjna została po raz pierwszy opisana przez Bruningsa w 1911 roku, a wprowadzona ponownie przez Arnolda w latach 60. XX wieku [1]. W ciągu ostatnich kilku dekad wykorzystywano do augmentacji różne preparaty, takie jak teflon, kolagen wołowy, autogenny czy homogenny, hydroxyapatyty wapniowe oraz tłuszcz autogenny. Idealny materiał do iniekcji powinien być łatwo osiągalny, niedrogi, dobrze tolerowany przez pacjenta, odporny na resorpcję, łatwy do zastosowania oraz całkowicie biokompatybilny [1-3]. W ostatnim czasie wielu fonochirurgów stosuje kwas hialuronowy (cross-linked), który nie daje odczynów zapalnych w obrębie fałdów głosowych [4]. Kwas hialuronowy jest ważnym składnikiem pozakomórkowej macierzy w lamina propria. Zapewnia po iniekcji właściwą lepkoelastyczność warstwy powierzchownej blaszki właściwej, wykazuje dość długą trwałość po wstrzyknięciu do fałdu głosowego oraz jak wskazują wstępne badania histologiczne ma zdolność pobudzania produkcji endogennego kolagenu, kwasu hialuronowego i fibroblastów [5,6]. Wyniki uzyskane po augmentacji fałdów głosowych kwasem hialuronowym we wczesnym okresie są szeroko opisywane w piśmiennictwie. Autorzy pracy własne doświadczenia przedstawili w poprzednich doniesieniach [7-10].

\section{Cel pracy}

Celem pracy była analiza struktury akustycznej głosu u pacjentów z jednostronnym porażeniem fałdu głosowego leczonych chirurgicznie metodą laryngoplastyki iniekcyjnej.

\section{Materiał i metody}

\section{Materiał}

Materiał pracy obejmował 42 osoby z jednostronnym porażeniem fałdu głosowego. Pacjenci prezentowali zaburzenia głosu o charakterze przewlekłej chrypki o różnym stopniu nasilenia, osłabienia, męczliwości i zaników głosu oraz trudności w wypowiadaniu dłuższych fraz. W badanej grupie było 18 mężczyzn i 24 kobiety w wieku od 21 do 77 lat (średnia wieku 53,7 lat). Wszyscy chorzy byli leczeni chirurgicznie metodą laryngoplastyki iniekcyjnej w Instytucie Fizjologii i Patologii Słuchu w Warszawie w latach 2010-2013.

Przyczyną porażenia fałdu głosowego była u 20 osób strumektomia (w tym u $4 \mathrm{z}$ powodu raka brodawkowatego tarczycy), u 2 guz podstawy czaszki, u kolejnych 2 operacja kardiochirurgiczna, w jednym przypadku operacja torbieli sródpiersia, u jednej osoby operacja raka przeły$\mathrm{ku}$, u jednej uraz krtani w trakcie intubacji do zabiegu w znieczuleniu ogólnym, u jednej operacja odcinka szyjnego kręgosłupa, u jednej uraz krtani w wyniku wypadku komunikacyjnego, a u 13 osób przyczyna porażenia nie została ustalona (idiopatyczne).

U 33 chorych stwierdzono porażenie lewego fałdu głosowego, w pozostałych 9 przypadkach prawego fałdu głosowego.

\section{Metody}

U wszystkich osób wykonano badanie laryngologiczno-foniatryczne, obejmujące laryngowideostroboskopię (LVS) oraz ocenę percepcyjną i akustyczną głosu. Badania były wykonywane przed zabiegiem oraz 12 i 24 miesiące po operacji fonochirurgicznej. Ocenę LVS krtani przeprowadzono przy użyciu aparatury EndoStrob DX Xion 327. W badaniu oceniano ustawienie porażonego fałdu głosowego oraz stopień zwarcia fonacyjnego, jako kryteria kwalifikujące do zabiegu laryngoplastyki iniekcyjnej.

Do oceny głosu pacjentów zastosowano opisaną przez Hirano w 1981 roku skalę Japońskiego Towarzystwa Logopedów i Foniatrów - GRBAS. W metodzie tej oceniano 
w skali od 0 do 3: stopień chrypki - G (grade), szorstkość głosu - R (roughness), głos o charakterze chuchającym B (breathiness), głos słaby - A (asthenic) oraz głos napięty $-\mathrm{S}$ (strained) [11].

Obiektywnej akustycznej oceny głosu dokonano za pomocą programu MDVP (Multidimensional Voice Program) i aparatury firmy KAY CSL. Do badania wykorzystano samogłoskę „a” w przedłużonej fonacji, którą zarejestrowano przy użyciu mikrofonu pojemnościowego AKG firmy KAY. Analizowano wartości wybranych parametrów akustycznych określających fizyczne cechy głosu. Z grupy parametrów oceniających względną zmianę częstotliwości analizie poddano Jita, Jitt, APQ, PPQ, sPPQ, vFo, Fo. Spośród parametrów oceniających względną zmianę amplitudy analizowano ShdB, Shim, APQ, sAPQ, vAm, a z grypy parametrów szumowych - NHR i SPI.

U 28 pacjentów zastosowano przedoperacyjną rehabilitację głosu obejmującą 1 sesję w tygodniu przez 2-3 miesiące, nie uzyskując zadowalającej poprawy głosu.

Wszystkich chorych z badanej grupy zakwalifikowano do laryngoplastyki iniekcyjnej z zastosowaniem kwasu hialuronowego (Surgiderm 24XP, Allergan). Zabiegi przeprowadzono w znieczuleniu ogólnym.

Preparat kwasu hialuronowego w ilości 0,3-0,8 ml wstrzykiwano jak najbliżej głębokiej warstwy blaszki właściwej porażonego fałdu głosowego, w punktach położonych ku przodowi, bocznie i przyśrodkowo od wyrostka głosowego, a w razie potrzeby w połowie długości fałdu, aby uzyskać wystarczające wypełnienie przestrzeni Reinkego w przednim odcinku fałdu. Celem zabiegu było przywrócenie właściwych warunków do tworzenia dźwięcznego głosu na poziomie głośni poprzez poprawę zwarcia fonacyjnego.

Uzyskane wyniki badań głosów pacjentów poddano analizie statystycznej, którą przeprowadzono z wykorzystaniem testu ANOVA, rang Friedmana, testu kolejności par Wilcoxona oraz współczynnika zgodności Kendalla. Za wartości istotne statystycznie przyjęto wartość współczynnika $\mathrm{p}$ na poziomie 0,05 .

\section{Wyniki}

U wszystkich pacjentów w badanej grupie w przedoperacyjnym badaniu LVS stwierdzono jednostronne porażenie fałdu głosowego ustawionego w pozycji przyśrodkowej (19 osób) lub odwiedzionej (23 osoby) oraz brak pełnego zwarcia podczas fonacji subiektywnie ocenionego na 1-2 mm, co było podstawowym kryterium kwalifikującym do laryngoplastyki iniekcyjnej. Po leczeniu chirurgicznym uzyskano u 23 osób pełne zwarcie fonacyjne, w 11 przypadkach pozostała niedomykalność w odcinku tylnym głośni, natomiast u 7 badanych pozostała niedomykalność wzdłuż całej szpary głośni, oceniona subiektywnie na poniżej $1 \mathrm{~mm}$ - były to osoby $\mathrm{z}$ odwiedzioną pozycją porażonego fałdu głosowego.

Po augmentacji zaobserwowano istotną statystycznie poprawę w zakresie wartości każdego analizowanego parametru skali GRBAS dla wszystkich okresów obserwacji. Ocena po 2 latach wykazała wzrost ich wartości stosunku do stanu rok po zabiegu, ale analiza statystyczna nie wykazała różnic pomiędzy 1 i 2 rokiem obserwacji $(\mathrm{p}<0,05)$.

Obiektywna analiza akustyczna głosu (MDVP) wykazała u wszystkich pacjentów poprawę struktury akustycznej głosu po zabiegu laryngoplastyki iniekcyjnej.

Wyniki analizy statystycznej wykonane testem ANOVA rang Friedmana oraz na podstawie współczynnika zgodności Kendalla i testu kolejności par Wilcoxona pokazały istotną statystycznie poprawę dla większości analizowanych parametrów oceniających względne zmiany częstotliwości. Najbardziej zauważalną poprawę uzyskano dla Jitt $(\mathrm{p}=0,03813), \operatorname{RAP}(\mathrm{p}=0,04076)$, PPQ $(\mathrm{p}=0,04076)$ i vFo $(\mathrm{p}=0,03813)$ po roku od zabiegu (ryciny 1 i 2$)$. Wartości Jita i sPPQ również uległy zmniejszeniu, ale różnica ta nie była istotna statystycznie $(\mathrm{p}=0,08487$ i $\mathrm{p}=0,2213)$. Poprawa struktury akustycznej głosu po upływie 2 lat od zabiegu utrzymywała się dla większości parametrów częstotliwościowych, $\mathrm{z}$ wyjątkiem Jita i vFo ( $\mathrm{p}=0,177115$ i $\mathrm{p}=0,099541$ ). Pomimo tego nie zaobserwowano istotnego pogorszenia wartości żadnego $\mathrm{z}$ analizowanych parametrów częstotliwościowych pomiędzy 1 i 2 rokiem po zabiegu $(\mathrm{p}<0,05)$.

Średnia wartość częstotliwości podstawowej Fo uległa zwiększeniu ze 196,6 Hz przed zabiegiem do $201,5 \mathrm{~Hz}$ rok po zabiegu i ponownemu zmniejszeniu do $196 \mathrm{~Hz} 2$ lata po zabiegu, jednak różnice te nie były istotne statystycznie (rycina 3).

Wśród parametrów opisujących zaburzenia amplitudy, istotną statystycznie poprawę po 12 miesiącach od zabiegu zaobserwowano dla APQ ( $\mathrm{p}=0,03813)$. Stabilne wyniki utrzymywały się również po upływie 2 lat po augmentacji $(\mathrm{p}<0,05)$. Wartości pozostałych analizowanych parametrów amplitudowych (ShdB, Shim, sAPQ i vAm) uległy zmniejszeniu rok i 2 lata po zabiegu w stosunku do wartości wyjściowych, jednak nie były to różnice istotne statystycznie (ryciny 4 i 5).

Nie zaobserwowano również istotnego pogorszenia wartości żadnego $\mathrm{z}$ analizowanych parametrów amplitudowych pomiędzy 1 i 2 rokiem po zabiegu $(\mathrm{p}<0,05)$.

W zakresie parametrów względnych pomiarów hałasu zaobserwowano istotne statystycznie zmniejszanie się średniej wartości NHR w kolejnych okresach obserwacji ( $\mathrm{p}=0,03813$ ), nie zaobserwowano również istotnego pogorszenia wartości tego parametru pomiędzy 1 i 2 rokiem po zabiegu $(\mathrm{p}<0,05)$ (rycina 6). Wartość SPI nie uległa istotnej statystycznie poprawie po zabiegu $(\mathrm{p}=0,28177)$, jednak pozostała stabilna 2 lata obserwacji $(\mathrm{p}<0,05)$ (rycina 7$)$.

\section{Dyskusja}

Laryngoplastyka iniekcyjna, obok tyreoplastyki medializacyjnej, jest aktualnie najczęściej wykonywaną procedurą chirurgiczną w leczeniu jednostronnych porażeń nerwów krtaniowych, w sytuacji, gdy rehabilitacja głosu jest nieskuteczna i przynosi niezadowalające efekty głosowe. W badanej grupie, jako materiał augmentacyjny, zastosowaliśmy preparat kwasu hialuronowego, opierając się na jego istotnych właściwościach. W obrębie fałdów 


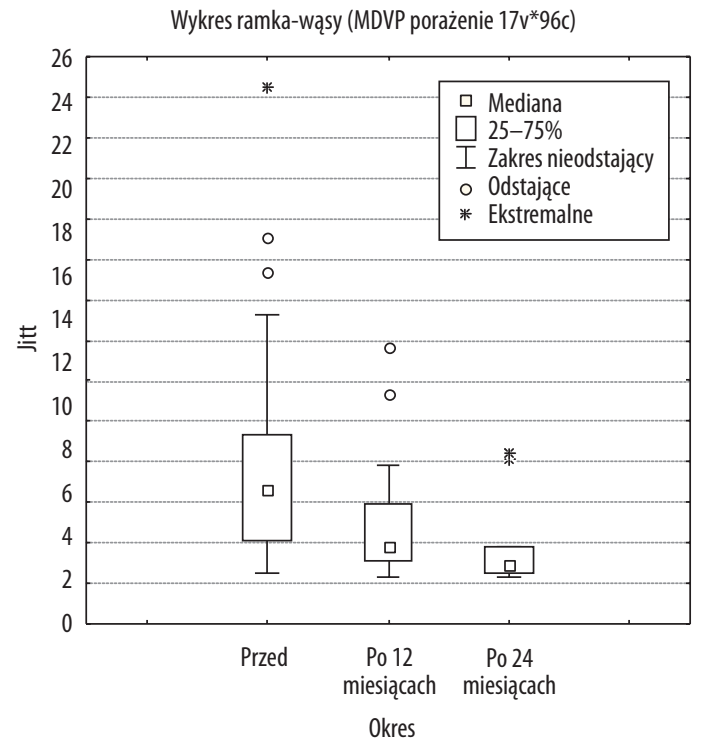

Rycina 1. Wyniki Jitt przed zabiegiem, 12 i 24 miesiące po augmentacji

Figure 1. Values of Jitt before surgery and 12 and 24 months after augmentation

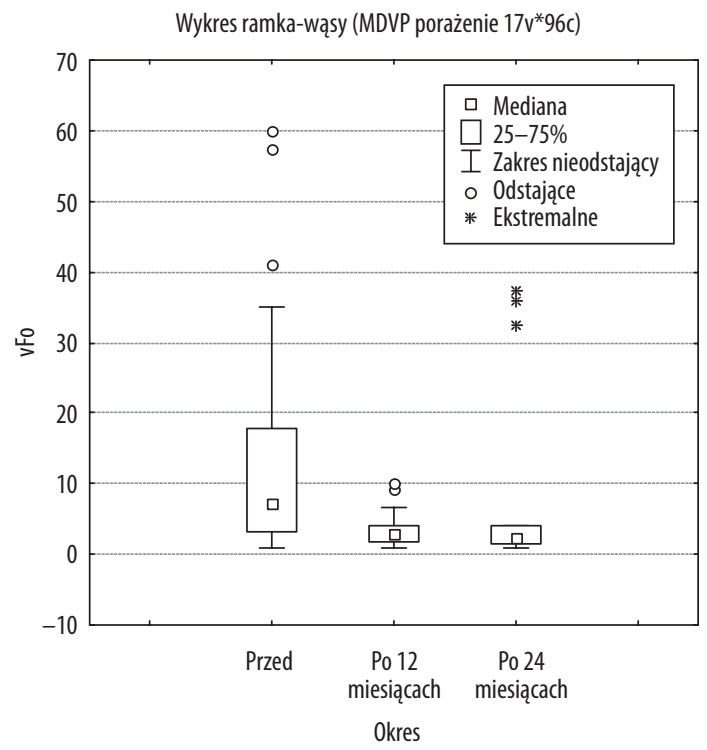

Rycina 2. Wyniki vFo przed zabiegiem, 12 i 24 miesiące po augmentacji

Figure 2. Values of vFo before surgery and 12 and 24 months after augmentation

głosowych odgrywa on kluczową rolę w utrzymaniu mechanicznej stabilizacji i elastyczności fałdów głosowych podczas fonacji, $w$ procesach regeneracyjnych, regulacji uwodnienia macierzy, nawilżeniu błony śluzowej, regulacji ciśnienia osmotycznego oraz stanowi barierę przeciw infekcjom [12].

Uzyskane wyniki pracy wskazują, że aplikacja kwasu hialuronowego do fałdów głosowych u osób z jednostronnym porażeniem fałdu głosowego przynosi dobre i bardzo

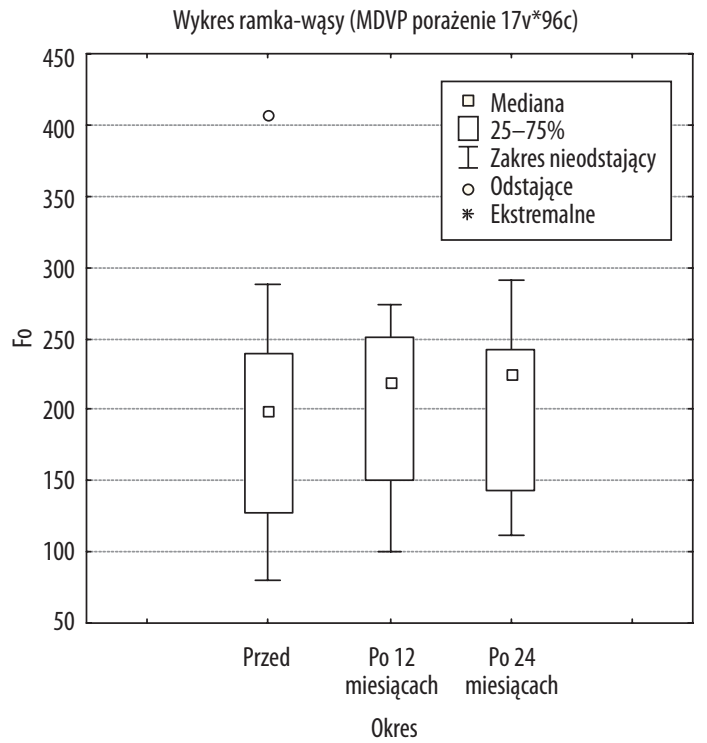

Rycina 3. Wyniki Fo przed zabiegiem, 12 i 24 miesiące po augmentacji

Figure 3. Values of Fo before surgery and 12 and 24 months after augmentation

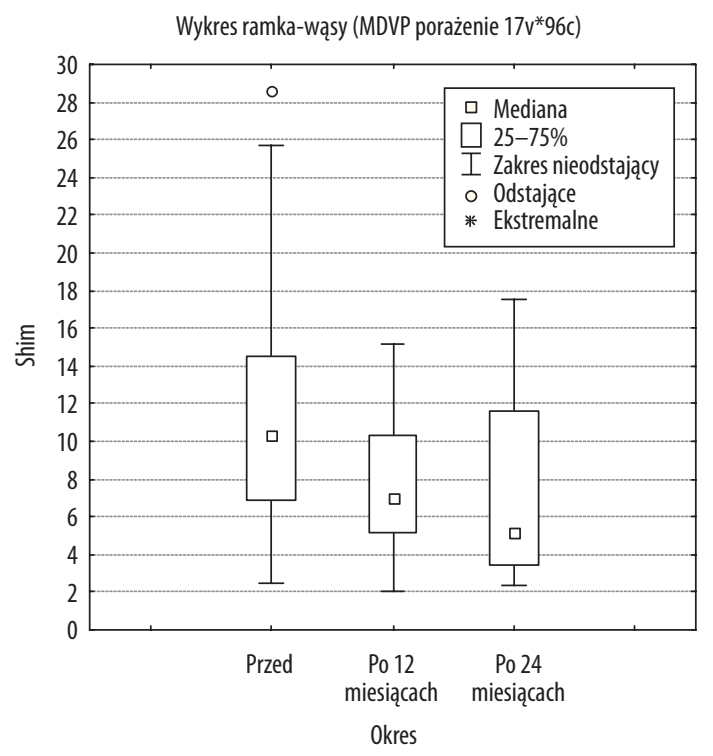

Rycina 4. Wyniki Shim przed zabiegiem, 12 i 24 miesiące po augmentacji

Figure 4. Values of Shim before surgery and 12 and 24 months after augmentation

dobre efekty, które utrzymują się co najmniej 2 lata po iniekcji. Subiektywna ocena głosu w skali GRBAS wykazała istotną statystycznie poprawę utrzymującą się rok i 2 lata po zabiegu. Dobrym obiektywnym wskaźnikiem poprawy głosu jest wieloparametryczna analiza akustyczna głosu MDVP. W tym badaniu największą poprawę uzyskaliśmy w grupie parametrów opisujących względne zmiany częstotliwości i poprawa ta utrzymywała się również w badaniach przeprowadzonych 2 lata po iniekcji. Jedynie wartość częstotliwości podstawowej Fo zmniejszyła się 


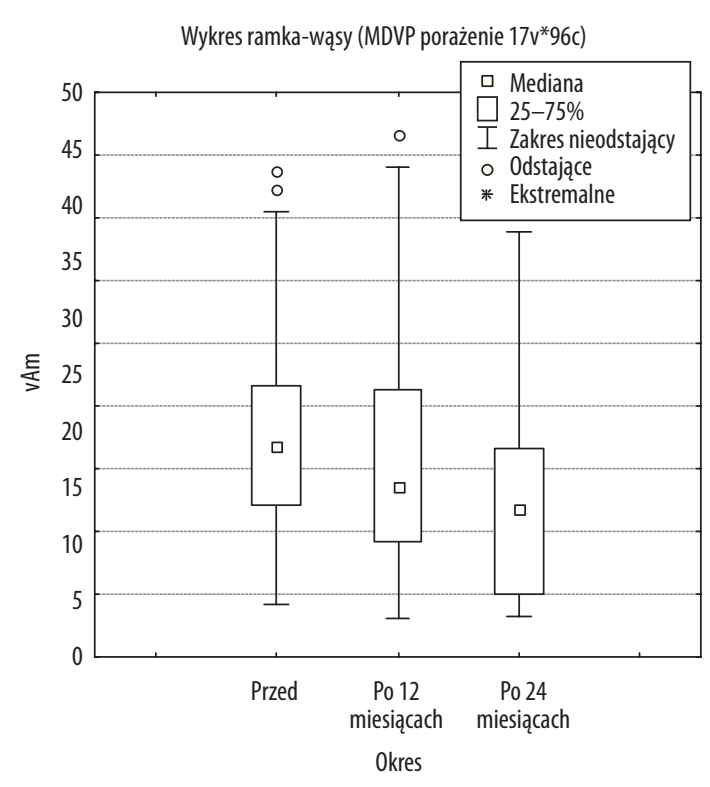

Rycina 5. Wyniki vAm przed zabiegiem, 12 i 24 miesiące po augmentacji

Figure 5. Values of vAm before surgery and 12 and 24 months after augmentation

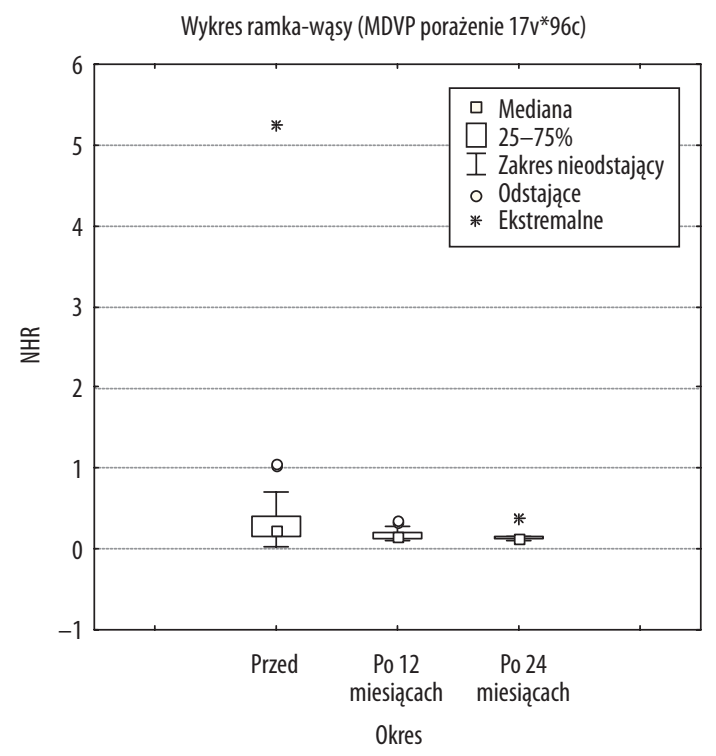

Rycina 6. Wyniki NHR przed zabiegiem, 12 i 24 miesiące po augmentacji

Figure 6. Values of NHR before surgery and 12 and 24 months after augmentation

nieistotnie statystycznie $(\mathrm{p}>0,05)$. Wartości analizowanych parametrów amplitudowych również uległy zmniejszeniu ( $p>0,05)$. Stabilizacja w zakresie parametrów szumowych potwierdziła poprawę zwarcia fonacyjnego i zmniejszenie niedomykalności na poziomie głośni. Nasze wyniki wskazują, że poprawa jakości głosu po augmentacji kwasu hialuronowego jest znacznie dłuższa, aniżeli można by się spodziewać po tym materiale iniekcyjnym [7-10]. Reiter i wsp. w grupie pacjentów z przedoperacyjną szparą fonacyjną 1-2 mm istotną statystycznie poprawę, utrzymującą

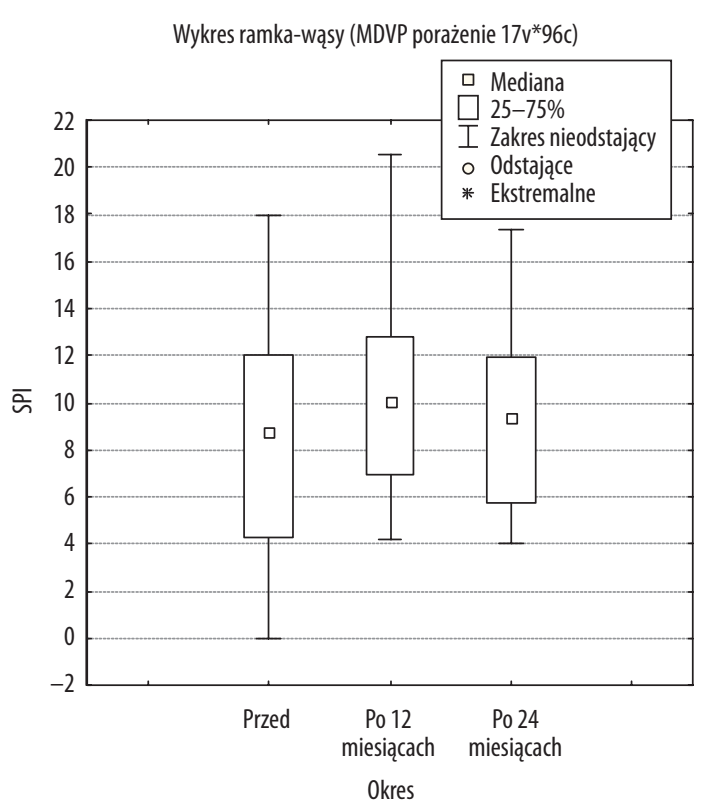

Rycina 7. Wyniki SPI przed zabiegiem, 12 i 24 miesiące po augmentacji

Figure 7. Values of SPI before surgery and 12 and 24 months after augmentation

się również po upływie 12 miesięcy po zabiegu, zaobserwował jedynie dla parametru shimmer. Przy niedomykalności około 2-3 mm poprawa wartości jitter i shimmer była krótkotrwała, a pogorszenie jakości głosu po upływie średnio 4,7 miesiąca tłumaczy, największą właśnie w okresie 4-6 miesięcy po iniekcji, resorpcją kwasu hialuronowego. Te wyniki potwierdzają również badania Hertegarda i wsp. [13,14].

U części pacjentów w badanej grupie pozostała niedomykalność na poziomie chrząstek nalewkowatych (tylny odcinek głośni), która z założenia jest trudna do korekcji przy pomocy augmentacji, co wpłynęło na niepełny efekt głosowy po zabiegu u tych pacjentów. Również w kryteriach kwalifikacyjnych należy uwzględniać stopień niedomykalności, gdyż szpara fonacyjna powyżej $3 \mathrm{~mm}$ rokuje niepełnym zwarciem pooperacyjnym także w części błoniastej szpary głośni [7].

Na końcowe efekty głosowe wpływa również czas, jaki upłynął od momentu wystąpienia porażenia, oraz to, czy pacjent przechodził rehabilitację głosu w okresie poprzedzającym augmentację, bowiem utrwalenie niewłaściwych nawyków emisyjnych jest trudne do wyeliminowania, nawet po zabiegu. W tym kontekście istotne znaczenie w kwalifikacji pacjentów do laryngoplastyki iniekcyjnej mogłoby mieć rutynowe wykonywanie badania elektromiografii krtani, które pozwoliłoby uniknąć niepotrzebnego wielomiesięcznego oczekiwania na ewentualny powrót czynności nerwu krtaniowego w przypadkach jego nieodwracalnego uszkodzenia. Wczesna augmentacja pozwoliłaby na szybkie wyrównanie anatomicznych nieprawidłowości na poziomie głośni i uniknięcie wytworzenia niekorzystnych nawyków emisyjnych. 


\section{Wnioski}

1. Laryngoplastyka iniekcyjna poprawia strukturę akustyczną głosu u pacjentów z jednostronnym porażeniem fałdu głosowego.

2. Najbardziej wyraźną poprawę uzyskuje się w zakresie parametrów częstotliwościowych oraz szumowych (NHR).
3. Stabilne wyniki utrzymują się do 2 lat po zabiegu.

4. Metoda laryngoplastyki iniekcyjnej z wykorzystaniem kwasu hialuronowego jest szybką i skuteczną metodą długotrwale poprawiającą strukturę akustyczną głosu w przypadku jednostronnego porażenia fałdu głosowego.

\section{Piśmiennictwo:}

1. Pearl AW, Woo P, Ostrowski R, Mojica J, Mandell DL, Costantino P. A preliminary report on micronized alloderm injection laryngoplasty. Laryngoscope, 2002; 112: 990-96.

2. Milstein CF, Akst LM, Hicks MD, Abelson TI, Strome M. Long-term effects of micronized alloderm injection for unilateral vocal fold paralysis. Laryngoscope, 2005; 115: 1691-97.

3. Rosen CA1, Gartner-Schmidt J, Casiano R, Anderson TD, Johnson F, Remacle M i wsp. Vocal fold augmentation with calcium hydroxylapatite: Twelve-month report. Laryngoscope, 2009; 119: 1033-41.

4. Remacle M, Lawson G. Injectable substances for vocal fold augmentation. Curr Opin Otolaryngol Head Neck Surg, 2001; 9: 393-97.

5. Molteni G, Bergamini G, Ricci-Maccarini A, Marchese C, Ghidini A, Alicandri-Ciufelli M i wsp. Auto-crosslinked hyaluronian gel injections in phonosurgery. Otolaryngol Head Neck Surg, 2010; 142: 547-53.

6. Dahlqvist $\mathrm{A}, \mathrm{Gärskog} \mathrm{O}$, Laurent $\mathrm{C}$, Hertegård $\mathrm{S}$, Ambrosio L, Borzacchiello A. Viscoelasticity of rabbit vocal folds after injection augmentation. Laryngoscope, 2004; 114: 138-42.

7. Miaśkiewicz B, Szkiełkowska A. Odległe wyniki w laryngoplastyce iniekcyjnej z zastosowaniem kwasu hialuronowego. Otorynolaryngol, 2014; 13(3): 147-54.
8. Szkiełkowska A, Miaśkiewicz B, Remacle M, Skarżyński H. Quality of voice after implantation of hyaluronic acid to the vocal folds - preliminary report. Otolaryngol Pol, 2011; 65(6): 214-18.

9. Szkiełkowska A, Miaśkiewicz B, Remacle M, Krasnodębska P, Skarżyński H. Quality of voice after augmentation of hyaluronic acid to the vocal fold. Med Sci Monit, 2013; 19: 276-82.

10. Miaśkiewicz B, Szkielkowska A, Piłka A, Skarżyński H. Assessment of acoustic characteristic of voice in patients after injection laryngoplasty with hyaluronan. Otolaryngol Pol, 2016; 70(1): 15-23.

11. Hirano M. Clinical Examination of Voice. Wien: Springer Verlag; 1981.

12. Branco A, Rodrigues SA, Fabro AT, Fonseca-Alves CE, Martins RH. Hyaluronic acid behavior in the lamina propria of the larynx with advancing age. Otolaryngol Head Neck Surg, 2014; 151(4): 652-56.

13. Reiter R, Brosch S. Laryngoplasty with hyaluronic acid in patients with unilateral vocal fold paralysis. J Voice, 2012; 26(6): 785-91.

14. Hertegård S, Hallén L, Laurent C, Lindström E, Olofsson K, Testad P i wsp. Cross-linked hualuronian versus collagen for injection treatment of glottal insufficiency: 2-year follow up. Acta Otolaryngol, 2004; 124: 1208-14 